\title{
Replication of IGF2-INS-TH*5 haplotype effect on obesity in older men and study of related phenotypes
}

\author{
Santiago Rodríguez ${ }^{1}$, Tom R Gaunt ${ }^{1}$, Elaine Dennison ${ }^{2}$, Xiao-he Chen ${ }^{1}$, Holly E Syddall ${ }^{2}$, \\ David IW Phillips ${ }^{2}$, Cyrus Cooper ${ }^{2}$ and Ian NM Day ${ }^{*}, 1$
}

${ }^{1}$ Human Genetics Division, University of Southampton, School of Medicine, Duthie Building (MP 808), Southampton
General Hospital, Tremona Road, Southampton, UK; ${ }^{2}$ Fetal Origins of Adult Disease Division, MRC Environmental
Epidemiology Unit, School of Medicine, Southampton University Hospital, Tremona Road, Southampton, UK

Interindividual variation of the IGF2-INS-TH region influences risk of a variety of diseases and complex traits. Previous studies identified a haplotype (designated IGF2-INS-TH*5 and tagged by allele A of IGF2 Apal, allele 9 of TH01 and class I alleles of INS VNTR) associated with low body mass index (BMI) in a cohort of UK men. We aimed here both to study whether previous findings relating * 5 with weight are replicated in a different cohort of men (East Hertfordshire) characterised in more phenotypic detail and to test the effect of this haplotype on related subphenotypes. The PHASE program was used to identify *5 and not*5 haplotypes. A total of 490 haplotypes were derived from 131 men and 114 women, the frequency of *5 being around $9 \%$. Specific tests of * 5 haplotype ( $v s$ not*5 haplotypes) conducted included Student's $t$-test and multiple regression analyses. We observed replication of weight effect for the * 5 haplotype in men: significant associations with lower BMI $\left(-1.81 \mathrm{~kg} / \mathrm{m}^{2}, P=0.009\right)$, lower waist circumference $(-6.3 \mathrm{~cm}$, $P=0.001)$ and lower waist-hip ratio $(-5 \%, P<0.001)$. This haplotype also marks nearly two-fold lower $120 \mathrm{~min}$ insulin $(P=0.004)$ as well as low baseline insulin $(-11.02 \mathrm{pmol} / \mathrm{I}, P=0.043)$ and low $30 \mathrm{~min}$ insulin $(-64.44 \mathrm{pmol} / \mathrm{l}, P=0.072)$ in a glucose tolerance test. No association between $* 5$ and these traits was found in women. Our results, taken together with other data on IGFII levels and TH activity, point to the importance of * 5 as an integrated polygenic haplotype relevant to obesity and insulin response to glucose in men.

European Journal of Human Genetics (2006) 14, 109-116. doi:10.1038/sj.ejhg.5201505; published online 26 October 2005

Keywords: obesity; IGF2-INS-TH genomic region; genetic association; replication; haplotype

Introduction

Adult obesity is a common multifactorial disorder, which causes or exacerbates many health problems including type II diabetes, coronary heart disease, hyperlipidaemia, hypertension, certain forms of cancer, respiratory complications and osteoarthritis of large and small joints. ${ }^{1,2}$

*Correspondence: Professor INM Day, Human Genetics Division, University of Southampton, School of Medicine, Duthie Building (MP 808), Southampton General Hospital, Tremona Road, Southampton S016 6YD, UK. Tel: + 44238079 4116; Fax: + 44238079 4264;

E-mail: I.N.M.Day@soton.ac.uk

Received 6 January 2005; revised 29 July 2005; accepted 16 September 2005; published online 26 October 2005
Body mass index (BMI), waist circumference (WC) and waist-hip ratio (WHR) are the most frequently used indicators of obesity and higher levels significantly reduce life expectancy. ${ }^{2,3}$ While BMI reflects obesity in general, WC and WHR are related to central obesity, that is, excess of body fat in the abdomen. ${ }^{4}$ It is well established that body weight and composition are substantially determined by genetic factors that are likely to be multiple and interacting, with most single variants producing only a moderate effect. ${ }^{5}$ Estimates of heritability for obesity, measured for BMI, have been found to be between 40 and $55 \%$ in most studies, although with estimates of up to $>80 \%$ in twin studies. ${ }^{6}$ Sex differences in heritability for 
BMI and evidence of sex-specific effects in BMI have been reported in a study of approximately 37000 complete twin pairs, suggesting that there may be differences between men and women in the genetic factors that influence variation of this trait. ${ }^{7}$ Over 600 genes, markers and chromosomal regions have been associated or linked with human obesity phenotypes. ${ }^{8}$ One such region is the IGF2INS-TH gene cluster on human chromosome 11p15. We have previously detected a polymorphic variant of IGF2 in humans that associates with 10\% differences in circulating levels of IGFII and is associated with adiposity in the Northwick Park Heart Study II (NPHSII), a cohort of unrelated UK Caucasian men. ${ }^{9}$ More detailed analyses of the most common microsatellite loci tagging haplotypes of the IGF2-INS-TH cluster as defined by a set of SNPs identified in IGF2, ${ }^{10}$ THO1 alleles ${ }^{11}$ and INS VNTR class I subclasses $^{12}$ has identified an extended haplotype designated IGF2-INS-TH*5 (hereafter *5), consisting of allele A of IGF2 ApaI, allele 9 of THO1 and a subset of class I alleles of INS VNTR, which is associated with lower BMI and fat mass in the NPHSII cohort. ${ }^{13}$ In vitro functional studies (references in Rodríguez et al $^{13}$ ) are also consistent with any gene of the IGF2-INS-TH cluster influencing weight. However, replication of genetic association in independent samples is important. ${ }^{14}$ In addition, significant results observed on related subphenotypes of a complex disease may provide further insight into possible mechanism. ${ }^{15}$

We present here a follow-up analysis of IGF2-INS-TH*5 haplotype in an independent cohort of unrelated Caucasian individuals in which weight association and relevant subphenotypes including response to glucose tolerance test (GTT) are examined.

\section{Materials and methods Study design}

The identification of the *5 haplotype was carried out as previously described. ${ }^{13}$ In brief, we used the PHASE program version $2.0^{16}$ in order to determine, with a predefined level of confidence set at $\geq 90 \%$, the two haplotypes resulting from the combination of the THO1 microsatellite and the SNPs IGF2 ApaI and INS HphI for each one of the individuals analysed. We have previously shown that the resulting haplotypes tag the most common haplotypes of 14 polymorphisms spanning this gene cluster, giving haplotypic analyses with an increased power (due to fewer missing data) and a reduced risk of false positive findings related to low-frequency haplotypes. ${ }^{13}$ The IGF2 ApaI, INS HphI and THO1 sites were genotyped as previously described (Rodríguez et al ${ }^{13}$ and references therein) from a sample of 245 unrelated UK Caucasian individuals (131 men and 114 women) from the East Hertfordshire cohort (EH). These subjects were selected from among all births in the county of Hertfordshire UK during 1911-1930, who were followed forward and found to be alive and still resident there in 1990 to 1995. All births in Hertfordshire, from 1911 onward were reported by the attending midwife and were recorded in ledgers. Health visitors saw the babies throughout infancy, and at 1 year of age, the babies were weighed. We computerised the ledger entries for these subjects. Using the National Health Service Central Register (NHSCR) at Southport, we traced the cohort. Twins, triplets, and singletons who died during childhood, and boys and girls for whom data on weight at birth and at 1 year of age were missing, were excluded. Data on many boys born in 1911-1923 were not submitted for tracing because forename, necessary for tracing, was not recorded. We could not trace girls born before 1923 because the new names on many who married could not be determined. Ledger details were insufficient to enable NHSCR to trace $15 \%$ of the boys and $27 \%$ of the girls. ${ }^{17}$ The subset selected for detailed evaluation of obesityrelated phenotypes comprised those willing to undergo an oral GTT, they did not differ significantly from the larger group in regard to birthweight or socioeconomic status. Both genders were nearly equally represented $(53.5 \%$ of men vs $46.5 \%$ of women), with similar age distributions: age ranging in men from 59 to 70.3 years (mean \pm $\mathrm{SE}=64.09 \pm 0.19$ ); and in women, from 60.3 to 71.5 years (mean $\pm \mathrm{SE}=64.00 \pm 0.18$ ). The 21 traits analysed were: birthweight, weight at 1 year, weight, height, BMI, WC, hip circumference, WHR, plasma triglycerides, systolic blood pressure, diastolic blood pressure, fasting plasma concentrations of proinsulin, traits related to oral GTT (plasma concentrations of insulin and glucose at baseline, at 30 and at $120 \mathrm{~min}$ after an oral load of $75 \mathrm{~g}$ of glucose, and insulin area under the curve during the GTT), and two homeostatic model assessment (HOMA) variables. The two HOMA variables analysed were HOMA- $\% \beta$ and HOMA- $\%$ S. Both models allow the deduction of $\beta$-cell function $(\% \beta)$ and insulin sensitivity (or resistance) $(\% \mathrm{~S})$, and have been validated against a variety of physiological methods. ${ }^{18}$ HOMA- $\% \beta$ and HOMA- $\%$ S were calculated from pairs of fasting glucose and insulin measurements as previously described. ${ }^{19,20}$ In addition, we analyse an overall variable of the metabolic syndrome, which was obtained as described in the Adult Treatment Panel III (ATP III) report. ${ }^{21}$ In short, five risk factors for metabolic syndrome were defined as present or absent for each individual according to established thresholds (see Table 8 from NCEP Expert Panel $^{21}$ ). The diagnosis of metabolic syndrome was made when three or more risk factors were present in a given individual. All subjects gave informed written consent, and permission to conduct the study was granted by the EH ethical committee.

\section{Statistical analysis}

As previously, ${ }^{13}$ we followed an additive haplotype-based model in this study. In keeping with the approach used in haplotype trend regression (HTR) ${ }^{22}$ and discussed more 
generally, ${ }^{23}$ each individual's phenotype (e.g. weight) was used twice, once for each observed (by inference) haplotype possessed. This is valid when Hardy-Weinberg equilibrium holds. ${ }^{22}$ The effect of the *5 haplotype on each trait was tested separately for men and women. Given prior hypothesis suggesting that *5 haplotype has an effect on weight, ${ }^{13}$ we compared, for each trait, the effect of this haplotype with the effect of the remaining haplotypes pooled together (defined here as not*5). The differences in the mean values observed for each trait between * 5 and not*5 were compared using the Student's $t$-test. One tailed test was used for replication test of *5 haplotype-BMI association. Adjustments for covariates were also performed using multiple regression analyses. We performed adjustments for age for analyses of all variables, and adjustments for WHR for obesity-related phenotypes. Noting a recently published claim relating the THO1 microsatellite with tobacco dependence ${ }^{24,25}$ and in order to correct for possible effects of this exposure on the phenotypes analysed, we also adjusted for smoking status in multiple regression analyses. The overall variable of metabolic syndrome (as defined by ATP III $^{21}$ ) was crosstabulated against the presence/absence of the *5 haplotype, and the association tested by a standard contingency table $\chi^{2}$ test (Pearson $\chi^{2}$ ). The following variables were logtransformed before statistical analyses and then retransformed for table presentation: plasma triglycerides, fasting plasma concentrations of proinsulin, insulin and glucose at baseline, plasma concentrations of insulin and glucose at 30 and at $120 \mathrm{~min}$ after an oral load of $75 \mathrm{~g}$ of glucose, insulin area under the curve during the GTT, HOMA- $\% \beta$ and HOMA- $\%$ S. The distributions of *5 and not*5 haplotypes were tested for normality for all phenotypes using the Kolmogorov-Smirnov goodness-of-fit test in order to check for the presence of possible outliers. The nonparametric Kruskal-Wallis test was also computed in order to check for concordance with the results obtained by multiple regression. The statistical analyses were conducted using SPSS (Windows version 10).

\section{Results}

Individual markers were all in Hardy-Weinberg equilibrium (data not shown). Tables 1 and 2 show the results obtained for ${ }^{*} 5$ and for not $^{*} 5$ haplotypes in men and women, respectively. All 21 phenotypes were normally distributed for both groups tested ( ${ }^{*} 5$ and not*5) both in men and in women $(P>0.05$ in the Kolmogorov-Smirnov goodness-of-fit test). No significant differences were observed between ${ }^{*} 5$ and not $^{*} 5$ in women (Table 2 ). In men, however, *5 associated with several traits (Table 1 and Figure 1). In accordance with previous evidence, ${ }^{13}$ haplotype *5 was found to show a significantly lower BMI when compared with not*5 in men $(P=0.0045)$. There is 1.81 unit BMI difference, whereas in the NPHSII study, *5 group averaged 0.84 units lighter than not*5 group. The corresponding mean reduction in weight observed for *5 in $\mathrm{EH}$ was $5 \mathrm{~kg}$ ( $2.4 \mathrm{~kg}$ in NPHSII). The results obtained from other obesity indicators confirm that ${ }^{*} 5$ has a significant protective effect against obesity in men. *5 shows lower WC by $6.3 \mathrm{~cm}$ and lower WHR by $5 \%$ (Table 1 ). The differences between * 5 and not* 5 are highly significant for BMI, WC and WHR even after adjustments for age and smoking in multiple regression analyses (Table 1). Our results also suggest that *5 has an effect on plasma proinsulin levels, and on plasma insulin and glucose levels both at baseline and after an oral GTT in men. A significant 1.5-fold reduction in plasma proinsulin levels was observed for *5 relative to not*5 (Table 1 ). However, this significant difference depends to some extent on weight, since the $P$ value is 0.131 after adjusting for WHR in multiple regression analysis. Plasma insulin levels after the glucose load in the oral GTT were also significantly lower for *5, the 120 min plasma insulin value remaining significant after adjustment for WHR (Table 1). The magnitudes of the differences observed in the oral GTT between *5 and not*5 for plasma insulin levels were as follows: lower values were found for *5 in baseline levels of insulin $(-11.0 \mathrm{pmol} / \mathrm{l})$, and in plasma insulin levels after $30 \mathrm{~min}(-64.4 \mathrm{pmol} / \mathrm{l})$ and after $120 \mathrm{~min}(-64.1 \mathrm{pmol} / \mathrm{l})$. These differences translate into a 1.4-fold lower insulin area under the curve during the oral GTT ( $P=0.015$, Table 1$)$. The differences in plasma glucose levels during the oral GTT between * 5 and not ${ }^{\star} 5$ were marginally significant: $0.41 \mathrm{mmol} / \mathrm{l}$ for baseline glucose, $0.82 \mathrm{mmol} / \mathrm{l}$ for glucose after $30 \mathrm{~min}$ and $0.87 \mathrm{mmol} / \mathrm{l}$ for glucose after $120 \mathrm{~min}, P$-values respectively $0.056,0.030$ and 0.076 . In addition, the results from multiple regression analysis also showed dependence of plasma glucose levels on WHR (Table 1). *5 associated also significantly with $\mathrm{HOMA}-\% \mathrm{~S}$, the magnitude of the effect observed being a reduction of $31 \%$ compared with the mean HOMA-\%S value observed for not*5 haplotypes. Again, this significant association was dependent on WHR (Table 1). The percentage of the variation explained for each trait, as measured by $R^{2}$, varied from 1.2 to $5.9 \%$ (Table 1). Although $R^{2}$ comparisons are difficult because they depend on the precision to which varables are measured (e.g. being more precise for plasma glucose and insulin levels than for WHR), these results suggest that the effects of * 5 on WHR, WC and plasma insulin 120 min may be larger than for the remaining variables (Table 1). No significant differences between $* 5$ and not* 5 were observed for birthweight, weight at 1 year, height, plasma TG, systolic BP, diastolic BP or HOMA- $\% \beta$ in men (Table 1 ). The nonparametric Kruskal-Wallis test confirmed all results obtained by parametric regression (Tables 1 and 2). On the other hand, there were no significant over- or underrepresentations of metabolic syndrome (as defined by ATP $\mathrm{III}^{21}$ ) for ${ }^{*} 5$ or not* 5 haplotypes either in men or in women. 
Table 1 Effect of the IGF2-INS-TH*5 haplotype on metabolic and cardiovascular risk traits in men

\begin{tabular}{|c|c|c|c|c|c|c|c|c|c|c|c|}
\hline \multirow[b]{2}{*}{ Phenotype } & \multicolumn{3}{|c|}{ *5 haplotype } & \multicolumn{3}{|c|}{ not*5 haplotypes } & \multirow[b]{2}{*}{$P_{1}$} & \multirow[b]{2}{*}{$R^{2}(\%)$} & \multirow[b]{2}{*}{$P_{2}$} & \multirow[b]{2}{*}{$P_{3}$} & \multirow[b]{2}{*}{$P_{4}$} \\
\hline & Mean & $S E^{\mathrm{a}}$ & $N$ & Mean & $S E^{\mathrm{a}}$ & $N$ & & & & & \\
\hline Birthweight (ounces ${ }^{b}$ ) & \multicolumn{2}{|c|}{$129.18 \pm 3.03$} & 22 & \multicolumn{2}{|c|}{$126.97 \pm 1.39$} & 240 & 0.637 & & & & 0.58 \\
\hline Weight 1 year (ounces $^{b}$ ) & \multicolumn{2}{|c|}{$365.23 \pm 5.52$} & 22 & \multicolumn{2}{|c|}{$366.12 \pm 2.82$} & 240 & 0.925 & & & & 0.972 \\
\hline Weight $(\mathrm{kg})$ & \multicolumn{2}{|c|}{$74.39 \pm 3.10$} & 22 & \multicolumn{2}{|c|}{$79.38 \pm 0.64$} & 240 & 0.015 & 1.8 & $0.019^{c}$ & $0.031^{d}$ & 0.007 \\
\hline Height (m) & \multicolumn{2}{|c|}{$1.73 \pm 0.01$} & 22 & \multicolumn{2}{|c|}{$1.72+0.00$} & 240 & 0.722 & & & & 0.543 \\
\hline $\operatorname{BMI}\left(\mathrm{kg} / \mathrm{m}^{2}\right)$ & \multicolumn{2}{|c|}{$24.91 \pm 1.01$} & 22 & \multicolumn{2}{|c|}{$26.72 \pm 0.19$} & 240 & 0.005 & 2.6 & $0.006^{c}$ & $0.009^{d}$ & 0.003 \\
\hline Waist circumf. (cm) & \multicolumn{2}{|c|}{$91.40 \pm 2.85$} & 22 & \multicolumn{2}{|c|}{$97.66 \pm 0.53$} & 240 & 0.001 & 3.9 & $0.002^{c}$ & $0.003^{d}$ & 0.001 \\
\hline Hip circumf. $(\mathrm{cm})$ & \multicolumn{2}{|c|}{$101.98 \pm 1.64$} & 22 & \multicolumn{2}{|c|}{$104.26 \pm 0.41$} & 240 & 0.112 & & & & 0.023 \\
\hline Waist:Hip (proportion) & \multicolumn{2}{|c|}{$0.89 \pm 0.01$} & 22 & \multicolumn{2}{|c|}{$0.94 \pm 0.00$} & 240 & 0.000 & 5.9 & $0.000^{c}$ & $0.000^{d}$ & 0.002 \\
\hline Systolic BP (mmHg) & \multicolumn{2}{|c|}{$157.68+5.64$} & 22 & \multicolumn{2}{|c|}{$163.12 \pm 1.44$} & 240 & 0.281 & & & & 0.376 \\
\hline Diastolic BP (mmHg) & \multicolumn{2}{|c|}{$88.14 \pm 2.84$} & 22 & \multicolumn{2}{|c|}{$90.10 \pm 0.69$} & 240 & 0.418 & & & & 0.630 \\
\hline Plasma TG $(\mathrm{mmol} / \mathrm{l})$ & 1.42 & 1.11 & 22 & 1.48 & 1.03 & 236 & 0.688 & & & & 0.660 \\
\hline Proinsulin (pmol/l) & 1.99 & 1.14 & 21 & 2.94 & 1.05 & 233 & 0.015 & 2.3 & $0.131^{\mathrm{e}}$ & $0.473^{f}$ & 0.015 \\
\hline Insulin $0(\mathrm{pmol} / \mathrm{l})$ & 31.50 & 1.12 & 20 & 42.52 & 1.04 & 232 & 0.043 & 1.6 & $0.313^{\mathrm{e}}$ & $0.680^{f}$ & 0.029 \\
\hline Insulin $30(\mathrm{pmol} / \mathrm{l})$ & 217.02 & 1.09 & 22 & 281.46 & 1.04 & 228 & 0.072 & 1.3 & $0.241^{\mathrm{e}}$ & $0.289^{f}$ & 0.041 \\
\hline Insulin $120(\mathrm{pmol} / \mathrm{l})$ & 87.36 & 1.20 & 21 & 151.41 & 1.06 & 223 & 0.004 & 3.3 & $0.021^{\mathrm{e}}$ & $0.095^{f}$ & 0.00 \\
\hline Insulin AUC OGTT & 18583 & 1 & 19 & 26370 & 1 & 215 & 0.015 & 2.5 & $0.086^{\mathrm{e}}$ & $0.186_{f}^{f}$ & 0.008 \\
\hline Glucose $0(\mathrm{mmol} / \mathrm{l})$ & 5.64 & 1.03 & 22 & 6.05 & 1.01 & 236 & 0.056 & 1.4 & $0.300^{\mathrm{e}}$ & $0.431^{f}$ & 0.071 \\
\hline Glucose $30(\mathrm{mmol} / \mathrm{l})$ & 8.67 & 1.04 & 22 & 9.49 & 1.01 & 236 & 0.030 & 1.8 & $0.271^{\mathrm{e}}$ & $0.621^{f}$ & 0.033 \\
\hline Glucose $120(\mathrm{mmol} / \mathrm{l})$ & 5.81 & 1.05 & 21 & 6.69 & 1.02 & 235 & 0.076 & 1.2 & $0.297^{\mathrm{e}}$ & $0.500^{f}$ & 0.091 \\
\hline НОМА- $\% \beta$ & 55.70 & 1.16 & 20 & 60.34 & 1.04 & 232 & 0.617 & & & & 0.33 \\
\hline HOMA-\%S & 1.40 & 1.12 & 20 & 2.03 & 1.04 & 232 & 0.019 & 2.2 & $0.264^{\mathrm{e}}$ & $0.674^{f}$ & 0.01 \\
\hline Age & 62.9 & 0.52 & 22 & 64.1 & 0.20 & 240 & 0.076 & 1.2 & & & 0.129 \\
\hline Smoker status $(\%)^{9}$ & $9.1 / 5$ & 31.8 & 21 & $17.5 / 6$ & /17.9 & 235 & $0.225^{h}$ & & & & $\mathrm{~N} / \mathrm{A}$ \\
\hline
\end{tabular}

The mean values, standard errors of the mean and number of haplotypes observed both for IGF2-INS-TH*5 and for the pool of remaining haplotypes are shown. $P_{1}$ and $R^{2}$ are, respectively, the $P$-values and the percentage of total variance explained by IGF2-INS-TH*5 for each trait, observed in the regression analyses without adjustments for covariates. $P_{2}$ and $P_{3}$ are the $P$-values observed in multiple regression analyses after adjusting for covariates as listed in the table footnotes. $P_{4}$ are the $P$-values obtained by the nonparametric Kruskal-Wallis test.

Bold values indicate $P<0.05$, and italic values indicate $0.05<P<0.1$

${ }^{a}$ Means and SE for plasma TG, proinsulin, insulin 0, insulin 30, insulin 120, insulin AUC OGTT, glucose 0, glucose 30 and glucose 120 are geometric, so that the geometric SE are multiples of the relevant means.

$\mathrm{b}_{1}$ ounce is $28.35 \mathrm{~g}$.

${ }^{\mathrm{c}}$ Adjusted for age.

dAdjusted for age and smoking.

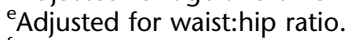

${ }^{\mathrm{f}}$ Adjusted for waist:hip ratio, age and smoking.

${ }^{9}$ Smoker status is given as percentage of never-, ex- and current-smokers, respectively.

${ }^{\mathrm{h}} P$-value obtained by a standard contingency table $\chi^{2}$ test (Pearson $\chi^{2}$ ).

The percentages of metabolic syndrome observed in men for each haplotypic group were $7.8 \%\left({ }^{*} 5\right)$ and $8.5 \%\left(\right.$ not $\left.^{\star} 5\right)$; the figures observed in women were $10 \%\left({ }^{*} 5\right)$ and $7.8 \%$ (not*5).

\section{Discussion}

This study describes the effects of IGF2-INS-TH*5 haplotype on two traits of clinical relevance: obesity and response to glucose. It both replicates evidence of the protective effect of *5 against obesity in men and extends detail on a range of relevant subphenotypes. The observed effect of $* 5$ on BMI is similar in both cohorts of men. The finding presented here for the first time that WC and WHR are significantly lower for *5 suggests that the reduction in BMI conferred by this haplotype occurs mainly via reduction of visceral obesity. The absence of association between * 5 and obesity-related phenotypes in women is in accordance with previous evidence suggesting differences between both sexes in the genetic factors influencing weight. ${ }^{7}$ The * 5 haplotype seems not to be associated with metabolic syndrome (as defined by ATP $\mathrm{III}^{21}$ ). This however does not argue against our results, since we have shown that ${ }^{*} 5$ associates with two out of the five risk factors established by ATP III, ${ }^{21}$ and this definition of metabolic syndrome assumes the presence of at least three of such risk factors.

The replication found in this study used a smaller sample size relative to our previous work. ${ }^{13}$ It has been suggested that the effect sizes may often be smaller in replication studies than in the initial study in which association has been reported. ${ }^{26}$ However, for this replication study, a simple dichotomy focused on the presence $v s$ absence of * 5 haplotype reduced 10-fold the need for Bonferroni correction (when considering haplotypes * 1 to *10), and justifiable one-sided test represented a more powerful test. In fact, the effect size was also larger. It could be argued that the multiple phenotypes examined would require a 
Table 2 Effect of the IGF2-INS-TH*5 haplotype on metabolic and cardiovascular risk traits in women

\begin{tabular}{|c|c|c|c|c|c|c|c|c|c|c|c|}
\hline \multirow[b]{2}{*}{ Phenotype } & \multicolumn{3}{|c|}{ *5 haplotype } & \multicolumn{3}{|c|}{ not*5 haplotypes } & \multirow[b]{2}{*}{$P_{1}$} & \multirow[b]{2}{*}{$R^{2}(\%)$} & \multirow[b]{2}{*}{$P_{2}$} & \multirow[b]{2}{*}{$P_{3}$} & \multirow[b]{2}{*}{$P_{4}$} \\
\hline & Mean & $S E^{\mathrm{a}}$ & $N$ & Mean & $S E^{\mathrm{a}}$ & $N$ & & & & & \\
\hline Birthweight (ounces ${ }^{b}$ ) & \multicolumn{2}{|c|}{$118.00 \pm 4.75$} & 20 & \multicolumn{2}{|c|}{$12166+128$} & 208 & 0.403 & & & & 0.523 \\
\hline Weight 1 year (ounces $^{\text {b }}$ ) & \multicolumn{2}{|c|}{$320.75 \pm 8.21$} & 20 & \multicolumn{2}{|c|}{$338.24 \pm 2.73$} & 208 & 0.058 & 1.6 & $0.057^{c}$ & $0.135^{d}$ & 0.091 \\
\hline Weight (kg) & \multicolumn{2}{|c|}{$69.45 \pm 2.53$} & 20 & \multicolumn{2}{|c|}{$68.55 \pm 0.76$} & 208 & 0.728 & & & & 0.943 \\
\hline Height $(\mathrm{m})$ & \multicolumn{2}{|c|}{$1.59 \pm 0.01$} & 20 & \multicolumn{2}{|c|}{$1.60+0.00$} & 208 & 0.595 & & & & 0.594 \\
\hline $\operatorname{BMI}\left(\mathrm{kg} / \mathrm{m}^{2}\right)$ & \multicolumn{2}{|c|}{$27.37+1.04$} & 20 & \multicolumn{2}{|c|}{$26.71 \pm 0.29$} & 208 & 0.502 & & & & 0.602 \\
\hline Waist circumf. (cm) & \multicolumn{2}{|c|}{$84.45 \pm 2.38$} & 20 & \multicolumn{2}{|c|}{$82.58 \pm 0.64$} & 208 & 0.398 & & & & 0.597 \\
\hline Hip circumf. (cm) & \multicolumn{2}{|c|}{$105.43 \pm 1.92$} & 20 & \multicolumn{2}{|c|}{$104.19+0.56$} & 208 & 0.515 & & & & 0.568 \\
\hline Waist:Hip (proportion) & \multicolumn{2}{|c|}{$0.80 \pm 0.01$} & 20 & \multicolumn{2}{|c|}{$0.79 \pm 0.00$} & 208 & 0.481 & & & & 0.374 \\
\hline Systolic BP (mmHg) & \multicolumn{2}{|c|}{$155.95 \pm 4.13$} & 20 & \multicolumn{2}{|c|}{$155.45+1.45$} & 208 & 0.917 & & & & 0.898 \\
\hline Diastolic BP (mmHg) & \multicolumn{2}{|c|}{$82.55+2.40$} & 20 & \multicolumn{2}{|c|}{$82.00 \pm 0.71$} & 208 & 0.820 & & & & 0.771 \\
\hline Plasma TG ( $\mathrm{mmol} / \mathrm{l})$ & 1.36 & 1.12 & 20 & 1.26 & 1.03 & 208 & 0.400 & & & & 0.389 \\
\hline Proinsulin $(\mathrm{pmol} / \mathrm{l})$ & 4.12 & 1.12 & 20 & 3.51 & 1.04 & 208 & 0.204 & & & & 0.234 \\
\hline Insulin $0(\mathrm{pmol} / \mathrm{l})$ & 48.52 & 1.12 & 20 & 44.31 & 1.04 & 208 & 0.472 & & & & 0.420 \\
\hline Insulin $30(\mathrm{pmol} / \mathrm{l})$ & 287.84 & 1.12 & 20 & 246.24 & 1.04 & 202 & 0.215 & & & & 0.077 \\
\hline Insulin $120(\mathrm{pmol} / \mathrm{l})$ & 244.03 & 1.17 & 20 & 226.85 & 1.05 & 208 & 0.642 & & & & 0.707 \\
\hline Insulin AUC OGT & 30025 & 1 & 20 & 26598 & 1 & 202 & 0.337 & & & & 0.314 \\
\hline Glucose $0(\mathrm{mmol} / \mathrm{l})$ & 5.65 & 1.02 & 20 & 5.65 & 1.01 & 208 & 0.990 & & & & 0.376 \\
\hline Glucose $30(\mathrm{mmol} / \mathrm{l})$ & 9.05 & 1.03 & 20 & 8.67 & 1.02 & 202 & 0.385 & & & & 0.241 \\
\hline Glucose $120(\mathrm{mmol} / \mathrm{l})$ & 6.81 & 1.06 & 20 & 7.02 & 1.02 & 208 & 0.650 & & & & 0.701 \\
\hline HOMA- $\% \beta$ & 89.12 & 1.09 & 20 & 82.27 & 1.03 & 208 & 0.498 & & & & 0.491 \\
\hline HOMA-\%S & 2.38 & 1.11 & 20 & 2.16 & 1.04 & 208 & 0.464 & & & & 0.345 \\
\hline Age & 63.4 & 0.46 & 20 & 64.0 & 0.19 & 208 & 0.351 & & & & 0.551 \\
\hline Smoker status $(\%)^{\mathrm{e}}$ & $40.0 / 4$ & /20.0 & 20 & $49.9 /$ & $4 / 8.7$ & 208 & 0.248 & & & & $\mathrm{~N} / \mathrm{A}$ \\
\hline
\end{tabular}

The mean values, standard errors of the mean and number of haplotypes observed both for IGF2-INS-TH*5 and for the pool of remaining haplotypes are shown. $P_{1}$ and $R^{2}$ are, respectively, the $P$-values and the percentage of total variance explained by IGF2-INS-TH*5 for each trait, observed in the regression analyses without adjustments for covariates. $P_{2}$ and $P_{3}$ are the $P$-values observed in multiple regression analyses after adjusting for covariates as listed in the table footnotes. $P_{4}$ are the $P$-values obtained by the nonparametric Kruskal-Wallis test.

Bold values indicate $P<0.05$, and italic values indicate $0.05<P<0.1$.

${ }^{a}$ Means and SE for plasma TG, proinsulin, insulin 0, insulin 30, insulin 120, insulin AUC OGT, glucose 0, glucose 30 and glucose 120 are geometric, so that the geometric SE are multiples of the relevant means.

$\mathrm{b}_{1}$ ounce is $28.35 \mathrm{~g}$.

${ }^{\mathrm{c}}$ Adjusted for age.

dAdjusted for age and smoking.

${ }^{\text {e}}$ Smoker status is given as percentage of never- ex-, and current-smokers, respectively.

Bonferroni correction for 21 independent tests. However, many of the traits are interrelated (e.g. all the weightrelated traits, all the GTT related traits, and systolic and diastolic BP), which reduces the number of independent tests conducted. A more realistic Bonferroni correction of 5 would leave most signals significant. In addition, it seems unlikely that a statistical artifact led to consistency both of significance and direction of haplotypic effects of *5 for two independent cohorts. On the contrary, the BMI findings and other trait features, taken together with our previous findings ${ }^{13}$ support that the associations found have a biological basis and argues against type-I error or possible biases of the sampling scheme followed (the later supported also by the fact that all 21 phenotypes were normally distributed for ${ }^{*} 5$ and not ${ }^{*} 5$ haplotypes). The replication found in this work has greater relevance given the high risk of false negative results expected for SNP and haplotype studies ${ }^{27}$ and the low replication rate reported for association studies of obesity. ${ }^{28}$ The recently reported association of an individual SNP in IGF2 with BMI, WC and fat percentage in 538 males from 92 extended Finnish families $^{29}$ also points to an effect of $I G F 2$, although the SNPs studied have not been related to our ${ }^{*} 1$ to ${ }^{*} 10$ haplotype classification. ${ }^{13}$ Other literature also suggests that the IGF2-INS-TH region may be important in obesity. ${ }^{30-38}$

The confirmation of *5 as a weight-lowering haplotype in men and our findings on related phenotypes suggest that the IGF2-INS-TH region harbours causal site(s) influencing obesity and insulin response to glucose. Haplotype association analyses per se do not permit estimation either of the physical location of a causal genetic variant or its support interval. However, the extended haplotype used, which combines multiallelic microsatellite information with SNPs, has proved to be more powerful than the analysis of each of its single constituents, since we have not found significant associations for IGF2 ApaI, INS HphI and THO1 in this data set (data not shown). Other approaches to determination of causal SNPs (e.g. Maniatis $e a^{3 l^{39}}$ ) may determine the presence of one or more causal sites on this haplotype. Our results, however, permit speculation about possible functional element(s) of * 5 . There is evidence in 

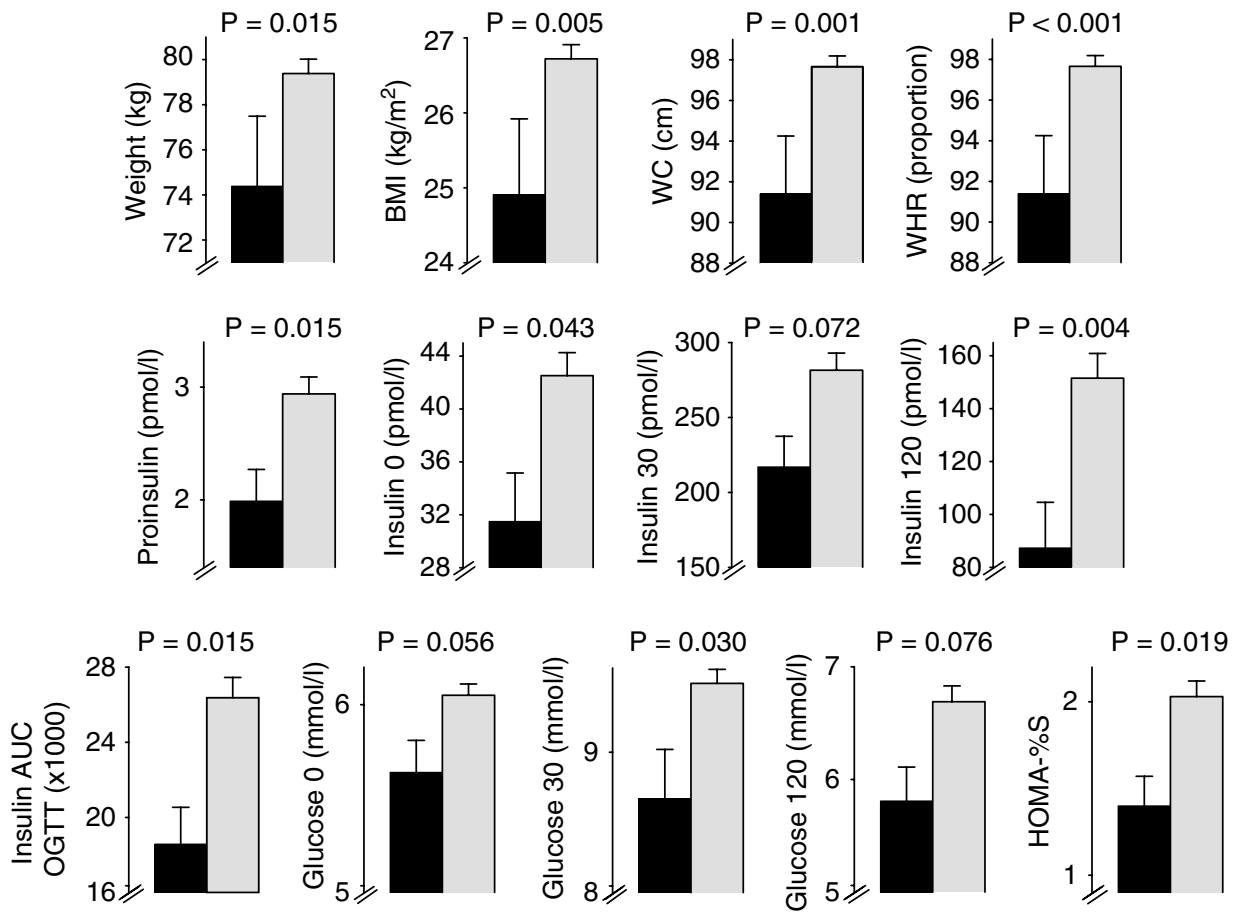

Figure 1 Graphical summary of the significant associations found for weight-related traits, response to insulin traits and HOMA-\%S in men. Black bars correspond to the ${ }^{5} 5$ haplotype and grey bars correspond to not* 5 haplotypes. The standard error of the mean is also shown for each case.

the literature involving all three genes, IGF2, INS and TH, in the regulation of body weight. It is known that insulin is a very efficient inhibitor of free fatty acid mobilisation. Insulin decreases the release of free fatty acids from adipose tissue by inhibiting hormone-sensitive lipase and stimulates triacylglycerol uptake into adipose tissue by activating lipoprotein lipase. ${ }^{33}$ Thus, a gradual decline in insulin secretion stimulates free fatty acid release from the adipose tissue. ${ }^{38}$ Therefore, a low expressor haplotype of insulin could be a primary determinant of lower weight. Indeed, we have observed in this work lower proinsulin and lower baseline plasma insulin levels in association with *5. However, it is also known that increase of insulin secretion in proportion to accumulated fat counteracts insulin resistance and protects individuals from hyperglycemia. ${ }^{40}$ Therefore, it is also possible that the lower insulin levels after an oral GTT found for * 5 could be secondary to the lesser insulin resistance of lean individuals. In this case (see below), IGF2 could contain the haplotypic determinants of the leanness.

Multiple regression results suggest that most of the insulin and glucose effects observed for * 5 are substantially dependent on WHR, a statistical pointer that the insulin and glucose associations of * 5 may be secondary to its weight effects. The same applies to the results we obtained for insulin sensitivity (or resistance) as measured by HOMA-\%S. However, the fact that plasma insulin levels 120 min after the oral GTT are significantly lower for *5 after adjustment for WHR, suggests a dual role of this haplotype on both phenotypes. Longitudinal studies may resolve these possibilities.

Previous evidence has related variation in the INS VNTR with control of insulin expression. However, the results obtained have been mutually inconsistent, some studies relating class I alleles with higher insulin levels, ${ }^{40-42}$ some showing association of class III alleles with increased insulin levels, ${ }^{43-45}$ and others reporting no effect of this VNTR on insulin level variation. ${ }^{46,47}$ The *5 haplotype contains INS VNTR class I alleles. However, it is not the only haplotype containing class I alleles (so do *1, *2, *3, ${ }^{*} 7, * 9, * 10$ ) whereas these haplotypes tested individually do not show weight effect (Rodríguez et $a l^{13}$ and this study) nor GTT effects (this study, data not shown). Indeed, our data suggest that the INS VNTR may not be the potential single causal site for the associations with weight and insulin response observed in the present study. This, however, does not exclude that the * 5 haplotype harbours a causal site determining expression of insulin and the shorter lengths of the small subclass of class I alleles associated with ${ }^{*} 5$ haplotypes could be relevant. ${ }^{48}$ Complete resequencing of this haplotype together with functional studies at the level of insulin expression may be necessary to search for such a putative causal site.

Association of class III homozygotes at the INS VNTR with greater birth weight has been reported, ${ }^{49}$ although more recent studies in Hertfordshire men, ${ }^{50}$ in other UK 
cohorts $^{51}$ and in a large Finnish birth cohort, ${ }^{52}$ did not corroborate this association. Neither did IGF2-INS-TH*5 haplotype associate with birth weight or weight at 1 year in Hertfordshire men in this analysis. *5 haplotype does not represent class III $v s$ class I but is associated with the subset of smallest class I alleles. Of additional note, *5 haplotype associated strongly with much lower $120 \mathrm{~min}$ insulin levels in a GTT (Table 1), whereas no major difference was observed comparing class I and class III homozygotes (data not shown).

The functional element(s) of *5, which determine the weight effect, could also reside in the $T H$ and/or IGF2 genes. It is known that visceral fat is more lipolytic in response to catecholamine stimulation than is subcutaneous fat. ${ }^{35}$ Also known is that the THO1 microsatellite located in intron 1 of the TH gene has a role in the transcription of this gene, which encodes the rate-limiting enzyme in catecholamine biosynthesis, transcription appearing to be inhibited in proportion to the number of repeats from 3 to 8 and with a counteracted effect for alleles above eight repeats. ${ }^{53}$ The lower visceral fat associated with *5 could reflect an increased lipolysis of visceral fat stimulated by catecholamines via a comparatively increased expression of $\mathrm{TH}$ conferred by the *5 constituent THO1 allele 9 (with a core of 9 repeats). However, it should be pointed out that haplotype *9 (containing THO1 allele 9) as well as haplotypes *3, *4 and *6 (all containing allele 9.3) do not show a weight-lowering effect. $^{13}$

Recent studies of IGFII suggest that this major fetal growth factor with effects on fetal skeletal muscle growth and development, which is also expressed in adult life, may be associated with lipid metabolism and obesity. The expression of an $I g f 2$ transgene in adult skin reduces the amount of body fat, ${ }^{30}$ whereas low plasma IGFII concentrations predict weight gain and obesity. ${ }^{54}$ Homozygotes for allele A at IGF2 ApaI site in the $3^{\prime}$ noncoding region show a mean body weight $3.3 \mathrm{~kg}$ lighter and show higher mean serum IGFII levels than the common (GG) homozygotes. ${ }^{9}$ It is plausible, therefore, that ${ }^{*} 5$ predicts high IGFII levels and that this high expressor status is a primary protection against obesity. However, previous evidence showing that haplotype ${ }^{*} 6$, which also contains IGF2 ApaI A allele, does not show a weight-lowering effect, $^{13}$ indicates that the ApaI site either has no functional effect or has effect conditional to other haplotypic elements.

In conclusion, our haplotypic analyses confirm that *5 has a protective effect against obesity in men and the investigation, for the first time, of its effect on related phenotypes, suggests that *5 may also be relevant to variation of insulin levels in GTT in men. IGF2, INS and TH are certainly haplotypically coupled and may conceivably be functionally (evolutionarily) coupled in their effect(s) both on weight and on insulin response to glucose.

\section{Acknowledgements}

The UK MRC is thanked for support.

\section{References}

1 Lamon-Fava S, Wilson PW, Schaefer EJ: Impact of body mass index on coronary heart disease risk factors in men and women. The Framingham Offspring Study. Arterioscler Thromb Vasc Biol 1996; 16: 1509-1515.

2 Kopelman PG: Obesity as a medical problem. Nature 2000; 404: $635-643$.

3 Friedman JM: Obesity in the new millennium. Nature 2000; 404: 632-634.

4 Sonmez K, Akcakoyun M, Akcay A et al: Which method should be used to determine the obesity, in patients with coronary artery disease? (body mass index, waist circumference or waist-hip ratio). Int J Obes Relat Metab Disord 2003; 27: 341-346.

5 Barsh GS, Farooqi IS, O'Rahilly S: Genetics of body-weight regulation. Nature 2000; 404: 644-651.

6 Feitosa MF, Borecki IB, Rich SS et al: Quantitative-trait loci influencing body-mass index reside on chromosomes 7 and 13 : the National Heart, Lung, and Blood Institute Family Heart Study. Am J Hum Genet 2002; 70: 72-82.

7 Schousboe K, Willemsen G, Kyvik KO et al: Sex differences in heritability of BMI: a comparative study of results from twin studies in eight countries. Twin Res 2003; 6: 409-421.

8 Perusse L, Rankinen T, Zuberi A et al: The human obesity gene map: the 2004 update. Obes Res 2005; 13: 381-490.

9 O'Dell SD, Miller GJ, Cooper JA et al: Apal polymorphism in insulin-like growth factor II (IGF2) gene and weight in middleaged males. Int J Obes Relat Metab Disord 1997; 21: 822-825.

10 Gaunt TR, Cooper JA, Miller GJ, Day IN, O'Dell SD: Positive associations between single nucleotide polymorphisms in the IGF2 gene region and body mass index in adult males. Hum Mol Genet 2001; 10: 1491-1501.

11 Puers C, Hammond HA, Jin L, Caskey CT, Schumm JW: Identification of repeat sequence heterogeneity at the polymorphic short tandem repeat locus HUMTH01[AATG]n and reassignment of alleles in population analysis by using a locusspecific allelic ladder. Am J Hum Genet 1993; 53: 953-958.

$12 \mathrm{Gu}$ D, O'Dell SD, Chen XH, Miller GJ, Day IN: Evidence of multiple causal sites affecting weight in the IGF2-INS-TH region of human chromosome 11. Hum Genet 2002; 110: 173-181.

13 Rodríguez S, Gaunt TR, O'Dell SD et al: Haplotypic analyses of the IGF2-INS-TH gene cluster in relation to cardiovascular risk traits. Hum Mol Genet 2004; 13: 715-725.

14 Cardon LR, Bell JI: Association study designs for complex diseases. Nat Rev Genet 2001; 2: 91-99.

15 Campbell H, Rudan I: Interpretation of genetic association studies in complex disease. Pharmacogenomics J 2002; 2: 349-360.

16 Stephens M, Donnelly P: A comparison of bayesian methods for haplotype reconstruction from population genotype data. Am J Hum Genet 2003; 73: 1162-1169.

17 Barker DJ, Winter PD, Osmond C, Margetts B, Simmonds SJ: Weight in infancy and death from ischaemic heart disease. Lancet 1989; 2: $577-580$.

18 Wallace TM, Levy JC, Matthews DR: Use and abuse of HOMA modeling. Diabetes Care 2004; 27: 1487-1495.

19 Matthews DR, Hosker JP, Rudenski AS, Naylor BA, Treacher DF, Turner RC: Homeostasis model assessment: insulin resistance and beta-cell function from fasting plasma glucose and insulin concentrations in man. Diabetologia 1985; 28: 412-419.

20 Levy JC, Matthews DR, Hermans MP: Correct homeostasis model assessment (HOMA) evaluation uses the computer program. Diabetes Care 1998; 21: 2191-2192.

21 NCEP Expert Panel: Executive Summary of The Third Report of The National Cholesterol Education Program (NCEP) Expert Panel on Detection, Evaluation, And Treatment of High Blood 
39 Maniatis N, Collins A, Gibson J, Zhang W, Tapper W, Morton NE: Positional cloning by linkage disequilibrium. Am J Hum Genet 2004; 74: 846-855.

Cholesterol In Adults (Adult Treatment Panel III). JAMA 2001; 285: 2486-2497.

22 Zaykin DV, Westfall PH, Young SS, Karnoub MA, Wagner MJ, Ehm MG: Testing association of statistically inferred haplotypes with discrete and continuous traits in samples of unrelated individuals. Hum Hered 2002; 53: 79-91.

23 Sasieni PD: From genotypes to genes: doubling the sample size. Biometrics 1997; 53: 1253-1261.

24 Anney RJ, Olsson CA, Lotfi-Miri M, Patton GC, Williamson R: Nicotine dependence in a prospective population-based study of adolescents: the protective role of a functional tyrosine hydroxylase polymorphism. Pharmacogenetics 2004; 14: 73-81.

25 Olsson C, Anney R, Forrest S et al: Association between dependent smoking and a polymorphism in the tyrosine hydroxylase gene in a prospective population-based study of adolescent health. Behav Genet 2004; 34: 85-91.

26 Colhoun HM, McKeigue PM, Davey-Smith G: Problems of reporting genetic associations with complex outcomes. Lancet 2003; 361: 865-872.

27 Neale BM, Sham PC: The future of association studies: gene-based analysis and replication. Am J Hum Genet 2004; 75: 353-362.

28 Redden DT, Allison DB: Nonreplication in genetic association studies of obesity and diabetes research. I Nutr 2003; 133: $3323-3326$.

29 Suviolahti E, Soro-Paavonen A, Silander K et al: Variants in IGF2IGF2AS-INS gene cluster on chromosome $11 \mathrm{p} 15$ are associated with obesity related traits in Finns. Atherosclerosis Supplements 2004; 5: 60.

30 Da Costa TH, Williamson DH, Ward A et al: High plasma insulinlike growth factor-II and low lipid content in transgenic mice: measurements of lipid metabolism. I Endocrinol 1994; 143: $433-439$.

31 Nezer C, Moreau L, Brouwers B et al: An imprinted QTL with major effect on muscle mass and fat deposition maps to the IGF2 locus in pigs. Nat Genet 1999; 21: 155-156.

32 Jeon JT, Carlborg O, Tornsten A et al: A paternally expressed QTL affecting skeletal and cardiac muscle mass in pigs maps to the IGF2 locus. Nat Genet 1999; 21: 157-158.

33 Jequier E, Tappy L: Regulation of body weight in humans. Physiol Rev 1999; 79: 451-480.

34 Jones BK, Levorse J, Tilghman SM: Deletion of a nucleasesensitive region between the Igf 2 and $\mathrm{H} 19$ genes leads to Igf2 misregulation and increased adiposity. Hum Mol Genet 2001; 10: 807-814.

35 Camp HS, Ren D, Leff T: Adipogenesis and fat-cell function in obesity and diabetes. Trends Mol Med 2002; 8: 442-447.

36 Rice T, Chagnon YC, Perusse L et al: A genomewide linkage scan for abdominal subcutaneous and visceral fat in black and white families: The HERITAGE Family Study. Diabetes 2002; 51: $848-855$.

37 Sandhu MS, Gibson JM, Heald AH, Dunger DB, Wareham NJ: Low circulating IGF-II concentrations predict weight gain and obesity in humans. Diabetes 2003; 52: 1403-1408.

38 van Dijk G, de Vries K, Benthem L, Nyakas C, Buwalda B, Scheurink AJ: Neuroendocrinology of insulin resistance: metabolic and endocrine aspects of adiposity. Eur J Pharmacol 2003; 480: $31-42$.
40 Le Stunff C, Fallin D, Schork NJ, Bougneres P: The insulin gene VNTR is associated with fasting insulin levels and development of juvenile obesity. Nat Genet 2000; 26: 444-446.

41 Bazaes RA, Petry CJ, Ong KK, Avila A, Dunger DB, Mericq MV: Insulin gene VNTR genotype is associated with insulin sensitivity and secretion in infancy. Clin Endocrinol (Oxf) 2003; 59: 599-603.

42 Dos Santos C, Fallin D, Le Stunff C, LeFur S, Bougneres P: INS VNTR is a QTL for the insulin response to oral glucose in obese children. Physiol Genomics 2004; 16: 309-313.

43 Vafiadis P, Bennett ST, Todd JA et al: Insulin expression in human thymus is modulated by INS VNTR alleles at the IDDM2 locus. Nat Genet 1997; 15: 289-292.

44 Pugliese A, Zeller M, Fernandez Jr A et al: The insulin gene is transcribed in the human thymus and transcription levels correlated with allelic variation at the INS VNTR-IDDM2 susceptibility locus for type 1 diabetes. Nat Genet 1997; 15: 293-297.

45 Ong KK, Petry CJ, Barratt BJ et al: Maternal-fetal interactions and birth order influence insulin variable number of tandem repeats allele class associations with head size at birth and childhood weight gain. Diabetes 2004; 53: 1128-1133.

46 Ahmed S, Bennett ST, Huxtable SJ, Todd JA, Matthews DR, Gough SC: INS VNTR allelic variation and dynamic insulin secretion in healthy adult non-diabetic Caucasian subjects. Diabetes Med 1999; 16: 910-917.

47 Hansen SK, Gjesing AP, Rasmussen SK et al: Large-scale studies of the HphI insulin gene variable-number-of-tandem-repeats polymorphism in relation to Type 2 diabetes mellitus and insulin release. Diabetologia 2004; 47: 1079-1087.

48 O'Dell SD, Bujac SR, Miller GJ, Day IN: Associations of IGF2 ApaI RFLP and INS VNTR class I allele size with obesity. Eur J Hum Genet 1999; 7: 821-827.

49 Dunger DB, Ong KK, Huxtable SJ et al: Association of the INS VNTR with size at birth. ALSPAC Study Team. Avon Longitudinal Study of Pregnancy and Childhood. Nat Genet 1998; 19: $98-100$.

50 Ong KK, Phillips DI, Fall C et al: The insulin gene VNTR, type 2 diabetes and birth weight. Nat Genet 1999; 21: 262-263.

51 Mitchell SM, Hattersley AT, Knight B et al: Lack of support for a role of the insulin gene variable number of tandem repeats minisatellite (INS-VNTR) locus in fetal growth or type 2 diabetesrelated intermediate traits in United Kingdom populations. J Clin Endocrinol Metab 2004; 89: 310-317.

52 Bennett AJ, Sovio U, Ruokonen A et al: Variation at the insulin gene VNTR (variable number tandem repeat) polymorphism and 2004; 53: 2126-2131.

53 Albanese V, Biguet NF, Kiefer H, Bayard E, Mallet J, Meloni R: Quantitative effects on gene silencing by allelic variation at a tetranucleotide microsatellite. Hum Mol Genet 2001; 10: $1785-1792$.

54 Sandhu MS, Gibson JM, Heald AH, Dunger DB, Wareham NJ: Low circulating IGF-II concentrations predict weight gain and obesity in humans. Diabetes 2003; 52: 1403-1408. early growth: studies in a large Finnish Birth Cohort. Diabetes 